\title{
CHILD MALTREATMENT CASES REFERRED TO SOHAG'S MEDICO- LEGAL DEPARTMENT, MINISTRY OF JUSTICE: RETROSPECTIVE AND PROSPECTIVE MEDICO-LEGAL EVALUATION
}

\author{
Ghada Ali Omran ${ }^{\text {a }}$,Sawsan El-Sharkawy ${ }^{a}$, Amr M. Abd Al-Karim ${ }^{\text {b }}$, Doaa M. El \\ Shehaby ${ }^{\mathrm{a} *}$ \\ a Department of Forensic Medicine \& Clinical Toxicology, Faculty of Medicine, Assiut \\ University, Egypt, ${ }^{\mathrm{b}}$ Sohag Medico-Legal Department, Ministry of Justice \\ Doaa M. El Shehaby* \\ Tel: $+\mathbf{2 0 1 0 0 7 3 6 1 7 1 8}$ \\ Contact@: drdoaamoh@aun.edu.eg \\ Submit Date 26-10-2020 \\ Revise Date 16-07-2021 \\ Accept Date 2021-07-17
}

Child maltreatment is a serious global problem in all socioeconomic groups. This can lead to serious, long-lasting physical and/or psychological damage that extends to adulthood. Aim of work: the present study aims to evaluate different medico-legal aspects of confirmed child maltreatment cases at Sohag's medico-legal department of the ministry of justice, retrospectively and prospectively with demographic description and comparative analysis between the two parts of the study. Methods: this study included confirmed cases of child maltreatment at Sohag's medico-legal department of the ministry of justice, retrospectively at the year 2011 (the year of 25th Egyptian revolution) data collected from the reported files and prospectively at the year 2017 data collected during the examination or autopsy of the confirmed analysis cases with of the perpetrators' relationship to the victims. Results: the retrospective part revealed 112 cases (81 living and 31 dead); the male-to-female ratio was 4:1. Physical maltreatment was predominant (46.4\%), followed by combined patterns $(34.8 \%)$ and then sexual abuse (14.3\%). The autopsy of the dead cases revealed that hemorrhagic shock was the main cause of deaths $(46.7 \%)$ followed by brain injury $(23.3 \%)$. The prospective analysis revealed 91 cases (51 living and 40 dead); the male-to-female ratio was 3:1. Physical abuse was predominant (45.1\%), followed by equal percentages of neglect and sexual abuse $(25.3 \%)$. The autopsy of the dead cases revealed that hemorrhage and asphyxia were the main causes of deaths $(47.5 \%$ and $37.5 \%$, respectively). Extrafamilial perpetrators (friends, neighbors, drivers, and teachers) were the most reported individuals in retrospective and prospective analyses with no sufficient data that could be collected in approximately onethird of the cases in 2011 and in more than one-fourth of the cases in 2017. Conclusion: forensic examination of child maltreatment cases at the Sohag governorate as one of the upper egypt governorates provided evidence on the magnitude of the problem in upper egypt. The comparison of the medico-legal aspects between the retrospective part in the revolution period and the prospective part of the post revolution period revealed that similar results of most studied aspects with little difference have been observed in the child maltreatment pattern, which might be related to post revolution's social circumstances in egypt.

Keywords: child maltreatment, domestic violence, medico-legal, perpetrators, emotional harm; upper egypt

\section{INTRODUCTION}

Child maltreatment refers to violence against children, which is a serious globalscale public health problem. A lack of understanding of its serious long-lasting consequences and the burden of the cost has hampered investment from the society (Sedlak et al., 2010).

The World Health Organization (WHO) defined child maltreatment as "the abuse and neglect that occurs to a child under 18 years of age." It includes all types 
of physical and/or emotional ill-treatment, sexual abuse, neglect, and commercial or other exploitation, which result in actual or potential harm to the health, survival, or development of the child (Abbasi et al., 2015). Child maltreatment can occur in the child's home, at schools, or in any community the child has interactions with (Leeb et al., 2008).

The factors that lead to child maltreatment may be intentional or accidental and can result in psychological harm, physical injury, maldevelopment, deprivation, or even death. Besides health and social consequences on the child, there is an economic impact that includes costs of hospitalization, mental health treatment, child welfare, and longer-term health costs (Jenny and Isaak, 2006).

Several social and psychological risk factors have been identified to be responsible for this problem. These risk factors may differ according to social and cultural contexts and can include factors such as the child's specific characteristics as low birth weight, prematurity, illness, or physical or mental handicapping and caregiver and family characteristics as the lower educational level of the parents, parent's unemployment, poverty, low socioeconomic status, large family size, young parental age, and lack of parental responsibility (Cavanagh et al., 2007).

Egypt is considered a developing country with many societal unstable familial patterns of parent/child interactions. Such an environment may cause an accumulation of frustrations associated with unemployment, illnesses, housing problems, and other stress factors related to insufficient income and low socioeconomic status. Such situations can lead to some sort of domestic violence ending with child maltreatment and even death (El-Elemi, Sahar, and Moustafa, 2013).

The inherent problem with studying child maltreatment globally is the uncertainty about its true incidence since it is a complex issue and difficult to study and carries social fear and stigma for acceptance of sharing studies and research on violence against children. Even its estimated incidence varies widely depending on the country, the method of research used, the definition of child maltreatment used, and the maltreatment pattern studied (Pinheiro, 2006 \& Abbasi et al., 2015).

The most accurate incidence data have been obtained from countries that have multiagency death review teams that analyze the causes of child fatalities, such as in the United States and Australia. The data from several low-income and developing countries are insufficient (Walsh et al., 2005). In Egypt, the Ministry of Justice holds medico-legal authority and is responsible for the examination of child maltreatment cases referred by the police. Determining the extent of child maltreatment and its characteristics is an essential aspect of the treatment program and prevention planning (Amany et al., 2017).

The present study aimed to medicolegally evaluate confirmed child maltreatment cases referred to Sohag's Medico-legal Department, Ministry of Justice, retrospectively in 2011 and prospectively in 2017, and to systematically assess the patterns, tools, consequences, and causes of death. Additionally, analyses of the victims' demographic characteristics and how the perpetrators were related were performed.

\section{MATERIAL \& METHODS}

\section{Study design}

A cross-sectional study design comprising two parts was implemented. The first part was a retrospective evaluation of legally confirmed cases of child maltreatment that were referred to Sohag's Medico-legal Department of the Ministry of Justice during the period from January 1, 2011, to December 30, 2011.

The second part was a prospective evaluation of legally confirmed cases of child maltreatment that were referred to 
Sohag's Medico-legal Department of the Ministry of Justice during the period from January 1, 2017, to December 30, 2017. The Egyptian law No. 126, 2008, considers the subject a child aged up to 18 years (Egyptian law No. 126 of 2008 at https://learningpartnership.org/resource /child-law-egypt-document-english).

Suspected child maltreatment cases are usually referred to the Medico-legal Department of the Ministry of Justice for confirmation after history taking, examination, and investigation. Only legally confirmed cases and not cases of false allegations were included as referred cases in this study.

\section{Methods}

The retrospective data were collected from patients' reports of Sohag's Medicolegal Department archives, using a checklist predesigned by the investigator, whereas the prospective data were collected through history taking and external examination or autopsy of confirmed cases. Assessment of emotional maltreatment was undertaken by a psychiatrist who considered the case as one that included emotional abuse if the case involved five or more of the 10 items listed below (Sandre et al., 2018):

- Feeling of low value

- Rejection at home

- Loneliness

- Perceptions that the family structure is wrong

- Perceptions of being obliged to give up rights for a sibling

- No participation in decision-making

- Hurt from improper treatment

- Neglected when sick

- Parents do not respond to needs

-Parental preferential prejudice toward sibling(s)

A gynecologist was the examiner in cases where in sexual maltreatment was suspected. The case was considered to be sexual abuse if the sex organs were touched by any one of the opposite or same sex for reasons other than health or medical purposes (Afifi et al., 2003). For our study, we did not distinguish the signs and symptoms of abuse and the degree or intensity of each item (Sandre et al., 2018).

\section{Ethical considerations}

Written permission was obtained from the legal authorities of Sohag's Medicolegal Department, Ministry of Justice. Ethical approval was obtained from the Medical Ethical Committee, Faculty of Medicine, Assiut University. Personal data (names and personal details) of the participants examined both living and autopsied cases, were treated confidentially. In all cases, informed consent was obtained from the caregiver before the examination.

\section{Statistical Analysis}

Data were analyzed using IBM SPSS version 22 (SPSS, Inc., Chicago, USA). Results were expressed as frequencies and percentages for qualitative data alongside mean \pm SD for quantitative data. Categorical variables were analyzed using the chi-square test $\left(\chi^{2}\right)$ and the Fisher exact test depending on the size of the data set. $\mathrm{P}$ values of $<0.05$ were considered statistically significant.

\section{RESULTS}

Fig. 1 shows the demographic criteria of the cases studied that revealed the highest number of child maltreatment cases confirmed by examination at Medico-legal Department in 2011 and 2017. They were children in the second decade of life. The highest number of child maltreatment cases in 2011 and 2017 were among males (the male-to-female ratio was $4: 1$ and 3:1, respectively). Rural areas of the Sohag Governorate were the most common localities of confirmed child maltreatment cases both in 2011 and 2017. 


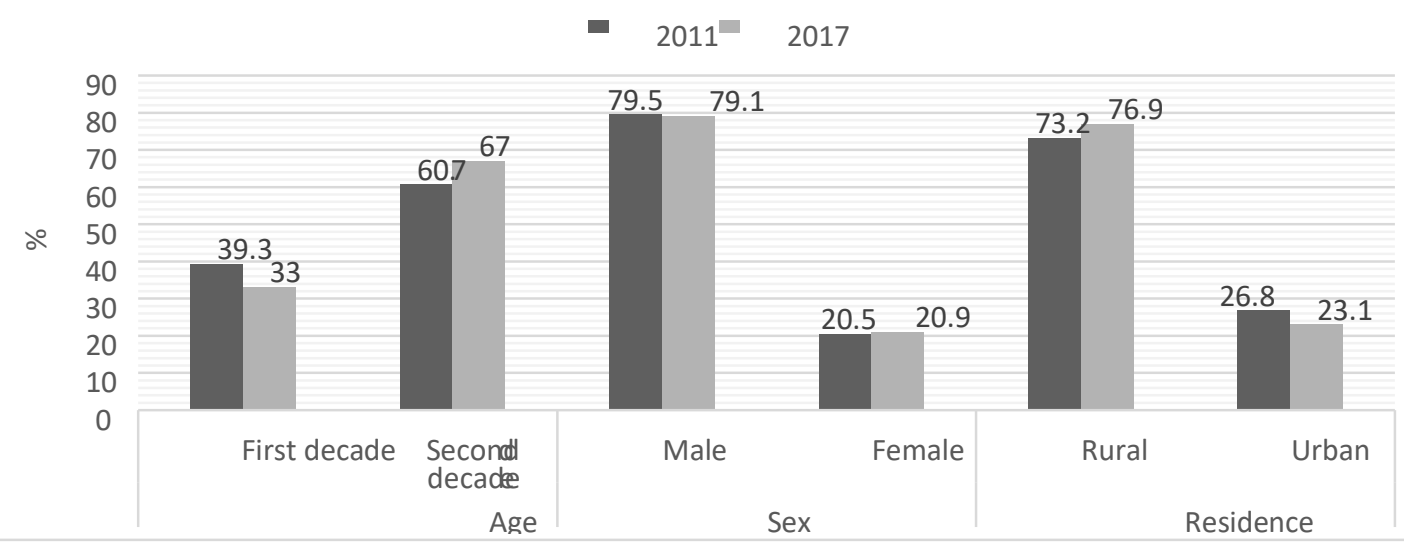

Figure (1): Demographic data of confirmed child maltreatment cases referred to Sohag's

Medico-legal Department in 2011 and 2017

Table 1 shows the reported patterns of child maltreatment and revealed that emotional abuse was reported in combination with all other patterns (physical, sexual, or neglect) in 2011 and 2017 (100\%). Physical abuse predominated in 2011 and 2017 (46.4\% and 45.1\%, respectively).

Sexual maltreatment was reported in $14.3 \%$ and $25.3 \%$, and neglect was reported in approximately $4.5 \%$ and $6.6 \%$ for all cases in 2011 and 2017, respectively. There were no significant differences between different maltreatment patterns between 2011 and 2017 ( $P=\mathbf{0 . 1 5 1})$.

Table (1): Patterns of confirmed child maltreatment cases referred to Sohag's Medico-legal

Department in 2011 and 2017

\begin{tabular}{|c|c|c|c|c|c|c|}
\hline \multirow{2}{*}{ Maltreatment type } & \multicolumn{4}{|c|}{ Year } & \multirow{2}{*}{$\boldsymbol{\chi}^{\mathbf{2}}$} & \multirow{2}{*}{$\begin{array}{c}\text { P } \\
\text { value }\end{array}$} \\
\cline { 2 - 6 } & \multicolumn{2}{|c|}{$\mathbf{2 0 1 1}$} & \multicolumn{2}{|c|}{$\mathbf{2 0 1 7}$} & \\
\cline { 2 - 5 } & No. & $\mathbf{\%}$ & No. & \% & & \\
\hline Neglect, Emotional & 5 & 4.5 & 6 & 6.6 & 5.94 & 0.115 \\
\hline Physical, Emotional & 52 & 46.4 & 41 & 45.1 & & NS \\
\hline Sexual, Emotional & 16 & 14.3 & 23 & 25.3 & & \\
\hline Physical, Emotional, Neglect & 39 & 34.8 & 21 & 23.1 & & \\
\hline
\end{tabular}

NS: Not significant $(P>0.05)$ Chi-squared test

Fig. 2 shows the tools used for child maltreatment in 2011 and reveals that firearms were the most common, $(37.5 \%)$ followed by blunt tools $(30.4 \%)$, and then poisons $(26.7 \%)$.

Conversely, Figure 3 shows the tools used for child maltreatment in 2017. Blunt tools $(64.8 \%)$ were the most common, followed by firearms $(17.6 \%)$, and then sharp instruments $(7.7 \%)$.

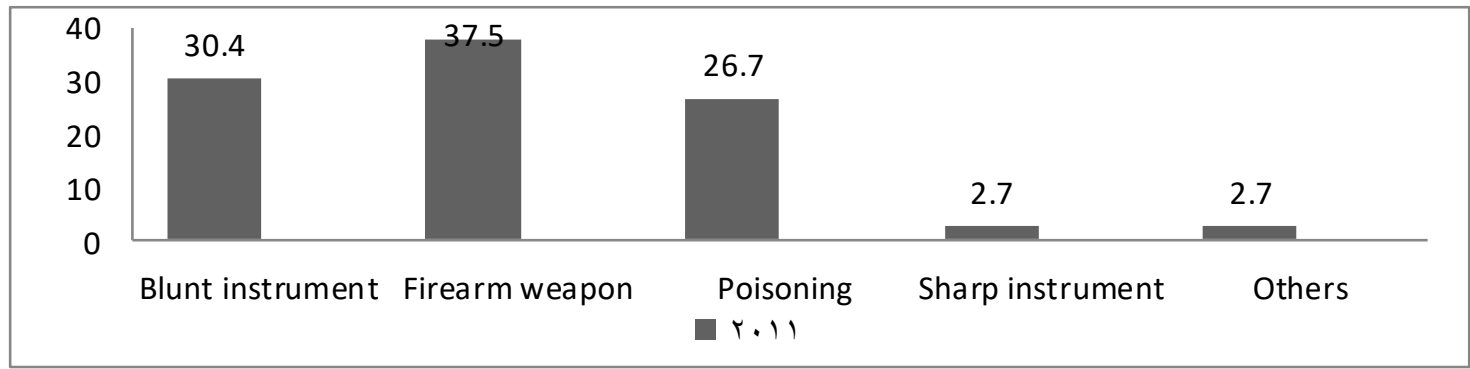

Others = drowning, combined tools

Figure (2): Tools used for confirmed child maltreatment cases referred to Sohag's Medicolegal Department in 2011 


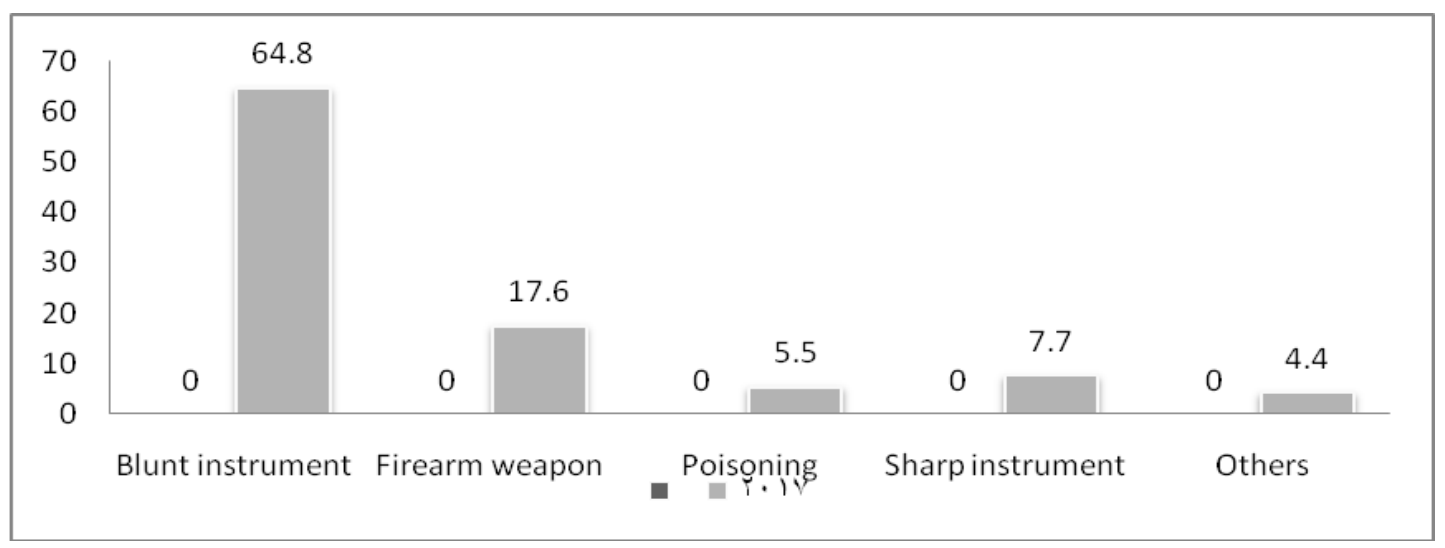

Figure (3): Tools used for maltreatment of confirmed child maltreatment cases referred to Sohag's Medico-legal Department in 2017

Table 2 shows the different contributing factors and associated circumstances with the child maltreatment cases analyzed in 2011 and 2017. The most common circumstances for child maltreatment were interpersonal violence followed by robberies in 2011.

Table 2: Contributing factors and circumstances associated with child maltreatment in the groups studied

\begin{tabular}{|c|c|c|c|c|c|}
\hline \multirow{2}{*}{$\begin{array}{l}\text { Contributing factors } \\
\text { and circumstances of child maltreatment }\end{array}$} & \multicolumn{2}{|c|}{2011} & \multicolumn{2}{|c|}{2017} & \multirow[b]{2}{*}{$P$ value } \\
\hline & No. & $\%$ & No. & $\%$ & \\
\hline Interpersonal violence & 47 & 42 & 21 & 23.1 & \multirow{10}{*}{$<0.001 * * *$} \\
\hline Robbery & 30 & 26.8 & 5 & 5.5 & \\
\hline Sexual behavior (rape, sodomy) & 13 & 11.6 & 22 & 24.2 & \\
\hline Kidnapping & 5 & 4.4 & 11 & 12 & \\
\hline Unwanted child & 3 & 2.7 & 5 & 5.5 & \\
\hline Revenge & 2 & 1.8 & 6 & 6.6 & \\
\hline Discipline & 2 & 1.8 & 1 & 1.1 & \\
\hline Circumcision & 1 & 0.9 & 1 & 1.1 & \\
\hline Poverty & 1 & 0.9 & 4 & 4.4 & \\
\hline Multiple associated circumstances and factors & 8 & 7.1 & 15 & $\mathbf{1 6 . 5}$ & \\
\hline
\end{tabular}

Others = drowning, burn Fisher's exact test

Table 3 shows the manner of injury or death associated with the circumstances of infliction of child maltreatment in the cases studied. It revealed that homicidal intent was present in most recorded cases, that is, $70.5 \%$ and $62.6 \%$ in 2011 and 2017, respectively, followed by non-intentional intent. Three suicidal cases were identified in 2011 as opposed to eight cases in 2017, with no statistically significant difference ( $\mathbf{P}=\mathbf{0 . 1 5 1}$ ) observed.

Table 4 shows permanent disabilities that occurred as a consequence of child
Conversely, in 2017, untoward sexual behavior was the most common, followed by interpersonal violence. The differences between the different circumstances of the child maltreatment observed were highly statistically significant between 2011 and 2017

(P<0.001).
*** Highly statistically significant $(\mathbf{P}<0.001)$ maltreatment detected via external examination and investigations. Permanent infirmities were recorded in $29.6 \%$ of the living cases in 2011 compared with their occurrence in $31.2 \%$ of those seen in 2017.

Skullbone defects were the most common disability, which were identified among maltreated children in 2011 and 2017 (37.4\% and $34.8 \%$, respectively), followed by limb fracture complications ( $29.2 \%$ and $31.2 \%$, respectively), and then impairments of special senses $(25 \%$ and $12.5 \%$, respectively). 
Table (3): Percentage distribution of manner associated with the circumstances of child maltreatment in the cases studied

\begin{tabular}{|c|c|c|}
\hline \multirow{2}{*}{ Manner } & \multicolumn{2}{|c|}{ Year } \\
\cline { 2 - 3 } & $\mathbf{2 0 1 1}(\mathbf{n}=\mathbf{1 1 2})$ & $\mathbf{2 0 1 7}(\mathbf{n}=\mathbf{9 1})$ \\
\cline { 2 - 3 } & No. (\%) & No. $(\%)$ \\
\hline Homicidal & $79(70.5 \%)$ & $62(68.1 \%)$ \\
\hline Accidental & $30(26.8 \%)$ & $21(23.1 \%)$ \\
\hline Suicidal & $3(2.7 \%)$ & $8(8.8 \%)$ \\
\hline
\end{tabular}

Table (4): Percentage distribution of permanent infirmity among confirmed child maltreatment (living cases) referred to Sohag's Medico-legal Department in 2011 and 2017 in the cases studied

\begin{tabular}{|l|c|c|}
\hline \multirow{2}{*}{ Permanent disability } & $\mathbf{2 0 1 1}$ & $\mathbf{2 0 1 7}$ \\
\cline { 2 - 3 } & $\begin{array}{c}\text { (No. of living } \\
\text { cases = 81) }\end{array}$ & $\begin{array}{c}\text { (No. of living } \\
\text { cases=51) }\end{array}$ \\
\hline Negative & $57(70.4 \%)$ & $35(68.8 \%)$ \\
\hline Positive & $24(29.6 \%)$ & $16(31.2 \%)$ \\
\hline $\begin{array}{l}\text { - Fracture complications (limitation of } \\
\text { movement, nonunion, and shortening) }\end{array}$ & $\mathbf{7 ( 2 9 . 2 \% )}$ & $\mathbf{5 ( 3 1 . 2 \% )}$ \\
\hline - Skullbone defects & $\mathbf{9 ( 3 7 . 4 \% )}$ & $\mathbf{7 ( 4 3 . 8 \% )}$ \\
\hline - Nerve injury (facial nerve palsy) & $\mathbf{1 ( 4 . 2 \% )}$ & $\mathbf{0 0 . 0 0}$ \\
\hline - Special senses (loss of vision, hearing defects) & $\mathbf{6 ( 2 5 \% )}$ & $\mathbf{2 ( 1 2 . 5 \% )}$ \\
\hline $\begin{array}{l}\text { - Others (female genital mutilation, } \\
\text { splenectomy) }\end{array}$ & $\mathbf{1 ( 4 . 2 \% )}$ & $\mathbf{2 ( 1 2 . 5 \% )}$ \\
\hline
\end{tabular}

Fig 4 shows the causes of death in the e cases studied and revealed hemorrhagic shock was the most common causes of death in 2011 and

2017(45.1\% and $47.5 \%$, respectively). In 2011, hemorrhagic shock was followed by brain injury $(25.8 \%)$ and then asphyxia and poisoning, whereas in 2017, hemorrhagic shock was followed by asphyxia $(37.5 \%)$, then poisoning and brain injury.
Table 5 shows the relationship between the different modes of child maltreatment in the cases studied with their years of occurrence. It revealed that a highly statistically significant relationship existed between the modes of child maltreatment and the year of occurrence. Firearms were most common in 2011, whereas blunt tools were the most common in

2017.

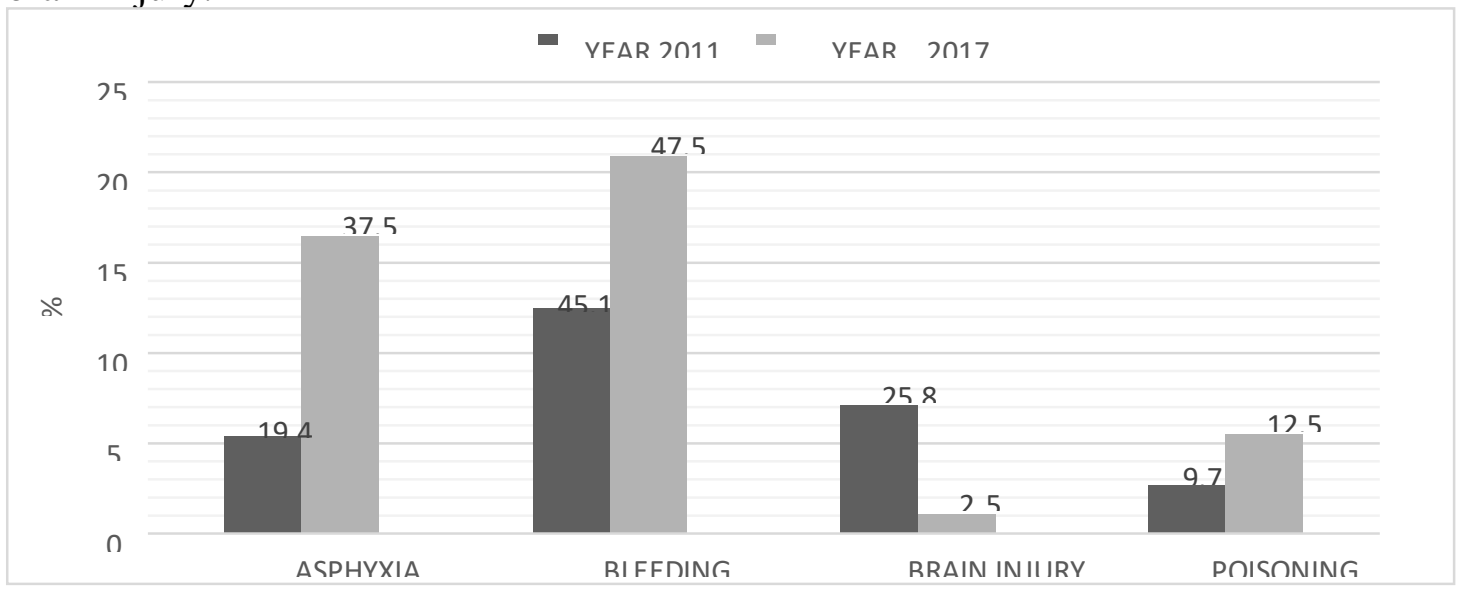

Figure (4): Distribution of different causes of death among dead child maltreatment cases referred to Sohag's Medico-legal Department in 2011 and 2017 
Table (5): Relationship of different tools of child maltreatment in cases studied with their years of occurrence (2011 and 2017)

\begin{tabular}{|c|c|c|c|c|c|}
\hline \multirow{2}{*}{ Tools of injury } & \multicolumn{4}{|c|}{ Year } & \multirow{2}{*}{ P value } \\
\cline { 2 - 5 } & \multicolumn{2}{|c|}{$\mathbf{2 0 1 1}$} & \multicolumn{2}{|c|}{$\mathbf{2 0 1 7}$} & \multirow{2}{*}{$<0.001 * * *$} \\
\cline { 2 - 5 } & No. & $\mathbf{\%}$ & No. & $\mathbf{\%}$ & \\
\hline Blunt instrument & 34 & 30.4 & 53 & 58.2 & \multirow{2}{*}{} \\
\hline Firearm weapon & 42 & 37.5 & 22 & 24.2 & \\
\hline Poisoning & 30 & 26.7 & 7 & 7.7 & \\
\hline Sharp instrument & 3 & 2.7 & 5 & 5.5 & \\
\hline Others(drowning-burn) & 3 & 2.7 & 4 & 4.4 & \\
\hline
\end{tabular}

*** Highly statistically significant $(\mathrm{P}<0.001)$ Fisher's exact test

Table 6 shows the relationship between permanent infirmities and the modes of child maltreatment among confirmed child maltreatment in 2011; $47.7 \%$ of cases without infirmities were due to firearms and $45.6 \%$ by blunt tools. Most limb complications (85.7\%) and skull bone defects $(77.8 \%)$ were identified to be due to blunt tools. In terms of other injuries, facial palsy was found to be due to firearms, whereas ear auricle loss and female genital mutilation were due to sharp tools. Finally, $80 \%$ of vision loss cases were identified to be due to firearms. This difference observed between modes of maltreatment was highly statistically significant $(\mathbf{P}<\mathbf{0 . 0 0 1})$.

Table 7 shows the relationship between permanent infirmities with modes of child maltreatment among confirmed child maltreatment cases in 2017 as well; $71.4 \%$ of cases without infirmities were due to blunt tools, followed by firearms $(20 \%)$. The majority of limb fracture complications $(80.0 \%)$ were due to blunt tools, which was the same result reported for skull bone defects, loss of vision, and spleen removal, whereas in the cases of ear auricle loss and female genital mutilation use of sharp tools was the main causative tool, with statistically significant difference (P

$=$

0.032).

Table (6): Permanent infirmity and the relationship between different modes of child maltreatment among confirmed child maltreatment cases (living cases) referred to Sohag's Medico-legal Department in 2011

\begin{tabular}{|c|c|c|c|c|c|c|}
\hline Permanent infirmity & Blunt & Sharp & Firearm & Poisoning & Total & $P$ value \\
\hline \multirow[t]{2}{*}{ No infirmity } & 26 & 3 & 27 & 1 & 57 & \multirow{15}{*}{$0.001 * *$} \\
\hline & $45.6 \%$ & $5.3 \%$ & $47.4 \%$ & $1.8 \%$ & $100.0 \%$ & \\
\hline \multirow[t]{2}{*}{ Limb complications } & 6 & 0 & 1 & 0 & 7 & \\
\hline & $85.7 \%$ & $0.0 \%$ & $14.3 \%$ & $0.0 \%$ & $100.0 \%$ & \\
\hline \multirow[t]{2}{*}{ Skullbone defects } & 7 & 0 & 2 & 0 & 9 & \\
\hline & $77.8 \%$ & $0.0 \%$ & $22.2 \%$ & $0.0 \%$ & $100.0 \%$ & \\
\hline \multirow[t]{2}{*}{ Facial palsy } & 0 & 0 & 1 & 0 & 1 & \\
\hline & $0.0 \%$ & $0.0 \%$ & $100.0 \%$ & $0.0 \%$ & $100.0 \%$ & \\
\hline \multirow{2}{*}{$\begin{array}{c}\text { Loss of vision in one } \\
\text { eye }\end{array}$} & 1 & 0 & 4 & 0 & 5 & \\
\hline & $20.0 \%$ & $0.0 \%$ & $80.0 \%$ & $0.0 \%$ & $100.0 \%$ & \\
\hline \multirow{2}{*}{$\begin{array}{c}\text { Ear auricle } \\
\text { loss }\end{array}$} & 0 & 1 & 0 & 0 & 1 & \\
\hline & $0.0 \%$ & $100.0 \%$ & $0.0 \%$ & $0.0 \%$ & $100.0 \%$ & \\
\hline \multirow{2}{*}{$\begin{array}{c}\text { Female genital } \\
\text { mutilation }\end{array}$} & 0 & 1 & 0 & 0 & 1 & \\
\hline & $0.0 \%$ & $100.0 \%$ & $0.0 \%$ & $0.0 \%$ & $100.0 \%$ & \\
\hline Total & 38 & 8 & 54 & 1 & 81 & \\
\hline
\end{tabular}

** Statistically significant $(\mathbf{P}<0.01: \leq 0.001)$ Fisher's exact test 
Table (7): Permanent infirmity and the relationship between different modes of child maltreatment among confirmed child maltreatment cases (living cases) referred to Sohag's Medico-legal Department in 2017

\begin{tabular}{|c|c|c|c|c|c|}
\hline Permanent infirmity & Bunt & Sharp & Firearm weapons & Total & P value \\
\hline No infirmity & $\begin{array}{c}25 \\
71.4 \%\end{array}$ & $\begin{array}{c}3 \\
8.6 \%\end{array}$ & $\begin{array}{c}7 \\
200 \%\end{array}$ & $\begin{array}{c}35 \\
1000 \%\end{array}$ & \multirow{6}{*}{$\begin{array}{c}\mathbf{0 . 0 3 2} \\
\text { NS }\end{array}$} \\
\hline \multirow{2}{*}{ Limb complications } & 4 & 0 & 1 & 5 & \\
\hline & $80.0 \%$ & $0.0 \%$ & $20.0 \%$ & $100.0 \%$ & \\
\hline \multirow{2}{*}{ Skullbone defects } & 7 & 0 & 0 & 7 & \\
\hline & $100.0 \%$ & $0.0 \%$ & $0.0 \%$ & $100.0 \%$ & \\
\hline \multirow{2}{*}{ splenectomy } & 1 & 0 & 0 & 1 & \\
\hline & $100.0 \%$ & $0.0 \%$ & $0.0 \%$ & $100.0 \%$ & \\
\hline \multirow{2}{*}{ Loss of vision in one eye } & 1 & 0 & 0 & 1 & \\
\hline & $100.0 \%$ & $0.0 \%$ & $0.0 \%$ & $100.0 \%$ & \\
\hline \multirow{2}{*}{ Ear auricle loss } & 0 & 1 & 0 & 1 & \\
\hline & $0.0 \%$ & $100.0 \%$ & $0.0 \%$ & $100.0 \%$ & \\
\hline \multirow{2}{*}{ Female genital mutation } & 0 & 1 & 0 & 1 & \\
\hline & $0.0 \%$ & $100.0 \%$ & $0.0 \%$ & $100.0 \%$ & \\
\hline \multirow[t]{2}{*}{ Total } & 38 & 5 & 8 & 51 & \\
\hline & $74.5 \%$ & $9.8 \%$ & $15.7 \%$ & $100.0 \%$ & \\
\hline
\end{tabular}

Table 8 shows the relationship between the perpetrators and the victims of child maltreatment. No sufficient data could be collected about the perpetrator in approximately $30 \%$ of the cases studied. Extrafamilial perpetrators (friends, neighbors, drivers, and teachers) were represented in approximately $44.6 \%$ in both 2011 and 2017. Intrafamilial relatives in the form of biological relatives (father, mother, brother, sister, cousin, and uncle) represented approximately $22.3 \%$ and $22 \%$ of perpetrators in 2011 and 2017, respectively, whereas nonbiological relatives (husband, wife of father, and husband of mother) represented $1.8 \%$ and $3.3 \%$ in 2011 and 2017, respectively. There were no statistically significant differences among perpetrators between 2011 and $2017(\mathbf{P}=\mathbf{0 . 8 5 5})$.

Table 8: Relationship between perpetrators and the victims of child abuse referred to Sohag's Medico-legal Department in 2011 and 2017

\begin{tabular}{|c|c|c|c|c|}
\hline \multicolumn{2}{|c|}{$\begin{array}{c}\text { Relationship between perpetrators victims } \\
\text { and the victims of child abuse }\end{array}$} & $\begin{array}{c}\mathbf{2 0 1 1} \\
\text { No=112\% }\end{array}$ & $\begin{array}{c}\mathbf{2 0 1 7} \\
\text { No = 91\% }\end{array}$ & P value \\
\hline Intrafamilial & $\begin{array}{c}\text { Biological relatives (father, mother, } \\
\text { brother, sister, cousin, uncle) }\end{array}$ & $25(22.3 \%)$ & $20(22 \%)$ & \\
\cline { 2 - 3 } & $\begin{array}{c}\text { Nonbiological relatives (husband, wife } \\
\text { of father, and husband of mother) }\end{array}$ & $2(1.8 \%)$ & $(3.3 \%) 3$ & \multirow{2}{*}{$\mathbf{0 . 8 5 5}$} \\
\hline \multicolumn{2}{|c|}{$\begin{array}{c}\text { Extrafamilial (friends, neighbors, drivers, and } \\
\text { teachers) }\end{array}$} & $50(44.6 \%)$ & $(44.6 \%) 42$ & NS \\
\hline \multicolumn{2}{|c|}{ No sufficient data could be collected } & $35(31.3 \%)$ & $27(31.3 \%)$ & \\
\hline
\end{tabular}

NS: Not significant $(P>0.05)$ Fisher's exact test 


\section{DISCUSSION}

The present study included legally confirmed cases of child maltreatment, referred for examination at Sohag's Medico-legal Department, Ministry of Justice in 2011 and 2017. Their numbers were 112 and 91, respectively, with most of the abused cases being in their second decade of life. This is consistent with the report of Arif et al. (2014) on a retrospective study among adolescent victims of sexual assaults in Lahore, wherein the age group of 11-18 years had the highest incidence of child abuse of a sexual nature.

Conversely, Al-Mahroos and AlAmer (2011) and Al-Madani et al. (2012) identified that in their study conducted in Dammam, Saudi Arabia, most child physical and sexual maltreatment cases were in the primary school age group (612 years). Males were the predominant victims in the present study in 2011 (4:1) and 2017 (3:1), which is consistent with studies on child abuse cases conducted in the United States (Tijaden \& Thoennes, 1988; Krug et al., 2002), wherein it was reported that boys are at higher risk of abuse especially of physical type. Generally, males are at greater risk for physical violence than girls, whereas girls face a greater risk of sexual assaults than do males. Furthermore, they are less likely to disclose abuse information, especially sexual abuse, and are less likely to share information with a stranger conducting a survey or even with medical doctors handling their cases (Afifi et al., 2003).

Rural areas of the Sohag Governorate as one of Upper Egypt governorates were the sites of higher referred cases of child maltreatment, which may be attributed to various community and social risk factors in the rural areas than in urban ones (CDC, 2016). This is in contrast to results from a study conducted to evaluate sexual assaults against children in the Suez Canal area, North Egypt, from 2004 to 2009, which revealed that those living in urban areas were affected more than those living in rural areas (Hagras et al., 2011).

The pattern of child maltreatment identified through examination of the referred cases to Sohag's Medico-legal Authority in 2011 and 2017 was a mixture of emotional, physical, sexual maltreatment, and neglect. Emotional abuse was reported in all these child maltreatment cases, which is consistent with the findings of Glaser (2002), Townsend (2013), and Weltz et al. (2016). Interestingly, this in contrast to the results of multiple cross-sectional studies from high-income countries (Australia, Canada, the United Kingdom, and the United States) that reported that only $10 \%$ of children suffer from psychological maltreatment, and rates in studies from Eastern European states (Macedonia, Latvia, Lithuania, and Moldovia), were between $12.5 \%$ and $33.3 \%$ of the cases (Gilbert et al., 2009), wherein the emotional problems identified in the child maltreatment cases studied may have been the primary maltreatment pattern or were present as a consequence of another pattern.

Physical abuse is the second most common pattern in the referred cases (46.4\%-45.1\% in 2011 and 2017, respectively). This is much higher than estimated in some studies of physical child maltreatment worldwide, which was estimated to be $13 \%$ in Sweden, 2006 (Janson et al., 2007), 25\% in England, 1999 (May \& Cawson, 2005), and 24\% in Denmark, 2008 (Gilbert et al., 2009).

We found that sexual abuse was the third common child maltreatment pattern in 2011 and 2017 with $25.3 \%$ and $14.3 \%$ cases, respectively. A meta-analysis conducted in 2009 analyzed child sexual abuse in 22 countries and revealed that 73 million boys and 150 million girls under the age of 18 years had experienced various forms of sexual violence (WHO, 2020). Wihbey (2011) studied the prevalence of child sexual abuse on different continents and reported the prevalence rates as $34.4 \%$ in Africa, $23.9 \%$ 
in Asia, $10.1 \%$ in America, and $9.2 \%$ in Europe.

Among the modes of physical child maltreatment in 2011, the use of firearms was the most common, followed by the use of blunt tools and poisons. The most common modes used in 2017 were the blunt ones and firearms. This was consistent with the 8th Report of the Maine Domestic Abuse Homicide Review Panel, 2010, which reported that the most common weapon used to kill the victims of domestic violence were firearms and then sharp tools, since males who are the predominant perpetrators typically use firearms and sharp weapons, whereas female perpetrators usually use blunt tools (Badawy et al., 2004). Another study on child abuse reported blunt trauma is the second common cause of physical child maltreatment cases, whereas others such as stabbing, drowning, and throttling were the least causes of childhood deaths (El-Elemi \& Moustafa, 2013).

Concerning contributing factors of child maltreatment in the present study, interpersonal violence was the most common, followed by robbery in 2011, which may be attributed to social and political circumstances that accompanied the January 25 revolution. Conversely, sexual behavior was the most common in 2017, which may be attributed to the fact that sexual behavior is a common cause of sexual maltreatment. It was higher in 2017 than in 2011, at $25.3 \%$ and $14.3 \%$, respectively. Motivations for child abuse can be classified into nonsexual and sexual; corporal punishment is the most prominent mode of nonsexual abuse even in developed countries (Radford et al., 2011).

Concerning the manner of injuries or deaths in cases referred to Sohag's Medico-legal Department, homicidal manner was the most common in the present study, and suicide by poisoning was most common in 2011, and that by asphyxia (hanging and drowning), in 2017. The higher percent of homicides may be attributed to corporal punishment, interpersonal violence, and circumstances with the force used in sexual assaults. This result is similar to the results of a retrospective study that was conducted in Cairo, Egypt, from 2006 to 2010 and reported similar higher homicidal child maltreatment $97.7 \%$ compared with other modes (Alsaif et al., 2013). A study on the violence in the United States reported that homicide is the leading cause of death for non-Hispanic blacks in the age period of 1-19 years, whereas it is the fifth most common cause of death among nonHispanic whites in this age range (Sumner et al., 2015).

Most of the permanent disabilities or infirmities observed in the present study as a consequence of child maltreatment were due to skullbone injuries, fracture complications (limitation of movement, nonunion, and shortening, amputation), followed by the impairment of special senses (loss of vision, loss ear auricle, and loss of hearing). This was more or less similar to the findings of DiScala et al. (2000) who studied the most commonly observed permanent disabilities following child abuse in newborns and children aged up to 4 years. They found old fractures in various stages of healing, chronic subdural hematomas, retinal hemorrhages, and skin infections related to poor hygiene. Victims of physical abuse in childhood are at risk for developing various permanently disfiguring injuries due to fracture complications (O'Donohue, 2018).

The autopsy of dead child maltreatment cases revealed higher deaths in 2017 than in 2011. The most common cause of death in 2011 and 2017 were hemorrhages due to firearm injuries, organ rupture, and perineum rupture in sexual child abuse cases. This is in contrast to the results of Alsaif et al. (2013), who reported head trauma and traumatic brain injury $(42 \%)$ as the most common cause of deaths, followed by bleeding and poisoning that occurred with emotional and neglect patterns of child maltreatment. 
Notably, asphyxia and brain injury were more common with physical and neglect than with other patterns.

The analysis of the perpetrators of the child abuse cases studied revealed that extrafamilial perpetrators (friends, neighbors, drivers, and teachers) were the most common perpetrators, which is in contrast to results of a study in the MedicoLegal Department, Suez Canal area, evaluating sexual assault against children from 2004 to 2009. That study reported 128 child abuse cases and that nearly $80 \%$ of the perpetrators were parents (Hagras et al., 2011). Additionally, current findings differ from another retrospective study conducted in Cairo, Egypt, from 2006 to 2010, wherein it was reported that the father was the perpetrator in approximately one-third of the cases (Alsaif et al., 2013).

In Nordic countries, a study reported that peers constituted $37 \%-48 \%$ of the perpetrators for girls and $23 \%-54 \%$ of the perpetrators for boys. Intrafamilial abusers constituted $1.5 \%-19 \%$ of the perpetrators in eight of the studies reviewed, whereas further three studies reported that in intrafamilial abuse the abusers were predominantly male relatives (other than the victim's father or stepfather; $30.2 \%$ ), family friends $(16.3 \%)$, neighbors $(15.6 \%)$, other known persons $(15.3 \%)$, or fathers or stepfathers $(13.5 \%)$, with victims both female and male, and $11 \%$ were victimized by a stranger (Jouriles et al., 2008). Furthermore, Grayston and De Luca (1999) reported that often, an existing relationship was found to be present between the child and the perpetrator.

The modes of child maltreatment and the year of infliction of injuries were identified to have a statistically significant relationship, as firearms were the most common mode in 2011, whereas blunt tools were the most common mode in 2017. This can be attributed to the fact that the January 25 revolution of Egypt, 2011, was accompanied by dramatic changes in the Egyptian community (Saad et al., 2016); consequently, these changes played a remarkable role in the increase in the usage of unlicensed weapons besides the increase in armed robberies (El Shehaby et al., 2018).

\section{CONCLUSION}

Forensic examination of child maltreatment cases at the Sohag Governorate as one of the Upper Egypt governorates provided evidence on the magnitude of violence against children in Upper Egypt. Comparison of the medicolegal aspects between the retrospective part in the Egyptian revolution period and the prospective part of the post revolution period revealed similar results of most aspects studied with little differences observed in the child maltreatment pattern that might be related to the January 25 revolution's circumstances in Egypt.

\section{RECOMMENDATIONS}

Guidelines to predict and diagnose child maltreatment cases should be implemented before they reach medicolegal departments. Careful examination of children by people with good knowledge of the injuries and signs indicative of different patterns of child maltreatment will accelerate the pace at which suitable help can be provided to the affected victims. The physical examination of a maltreated child by the forensic pathologist must include details about every part and every system in the body. In cases of potential victims of sexual abuse, the examination must be done as soon as possible. Prevention and dealing with the problem of child abuse requires a multidisciplinary approach with great effort and coordination among the public administration, numerous professionals, families, victims, and society.

\section{Abbreviations}

WHO: World Health Organization

CDC: Centers for Disease Control

CSA: child sexual abuse

\section{Competing interests}

The authors declare that there are no conflicts of interest.

Funding:The authors received no funding for this work. 


\section{REFERENCES}

Abbasi, M.A., MasumehSaeidi, G.K., Hoseini, B.L., and Moghadam, Z.E. (2015): Child maltreatment in the worldwide: a review article. International Journal of Pediatrics, 3, N.1-1.

Hagras, A.M., Moustafa, S.M., Barakat, H.N., and El-Elemi, A.H. (2011): Medico-Legal evaluation of child sexual abuse over a six-year period from 2004 to 2009 in the Suez Canal area, Egypt. Egyptian Journal of Forensic Sciences, 1:58-66.

Afifi, Z.E.M., El Lawindi, M.I., Ahmed, S.A., and Basily, W.W. (2003): Adolescent abuse in a community sample in BeniSuef, Egypt: Prevalence and risk factors, EMHJ-eastern Mediterranean Health. Journal, 9:1003-1018.

Al-Madani, O., Bamousa, M., Alsaif, D., Kharoshah, M.A.A., and Alsowayigh, K. (2012): Child physical and sexual abuse in Dammam, Saudi Arabia: A descriptive case-series analysis study. Egyptian Journal of Forensic Sciences:33-37.

Al-Mahroos, F. and Al-Amer, E. (2011): Reported child sexual abuse in Bahrain: 2000-2009. Annals of Saudi Medicine, 16:455-459.

Abd El Rahman, A.E., Azab, S.M.S., and Ramadan, M. (2017): Study of cases of child sexual abuse referred for medico-legal examination in Cairo and Giza, Egypt, 2007-2011. Journal of Child Sexual Abuse, 26:308-318. 10.1080/10538712. 1282574.

Arif, M. (2014): Medicolegal analysis of child and adolescent victims of sexual assault in Lahore- a retrospective study: Ahmed M and Chaudhary K M. Professional Medical Journal, 8:980986.

El-Elemi, A.H. and Moustafa, S.M. (2013): Review of 89 autopsies of child deaths from violence and neglect in the Suez Canal area, Egypt. Egyptian Journal of Forensic Sciences,
3:116-122.

Kandeel, F., Badawy, S., El-Seidy, A., and Gergis, N. (2014): A prospective study of some medicolegal aspects of physical and sexual family violence cases at Menoufia University hospital over 2 years. Menoufia Medical Journal, 27:122-129.

Cavanaugh, K., Donbas, R.E., and Dubach, R.P. (2007): The number of children by fathers in the context of child abuse. Child Abuse \& Neglect, 31:731.e46.

Centers for Disease Control and Prevention, (2016): Preventing child abuse and neglect: a technical package for policy, norm, and programmatic activities division of violence prevention.

DiScala, C., Sege, R., Li, G., and Reece, R.M. (2000): Child abuse and unintentional injuries: A 10-year retrospective. Archives of Pediatrics \& Adolescent Medicine, 154:16-22.

Egyptian Law No. 126 of 2008. Available from:

https://learningpartnership.org/resourc e/child-law-egypt:document-english.

El Shehaby, D., Saleh, M., Shahine, M., and Sayed, M.M. (2018): Did January 25th Egyptian Revolution Change the Medico-Legal Pattern and the Trend of Hospitalized Injuries in Upper, Egypt? A retrospective study. Egyptian Journal of Forensic Sciences \& Applied Toxicology, 18:15-27. 10.21608/ejfsat.2018.4609.1019.

El-Elemi, A.H. and Moustafa S M. (2013): Review of 89 autopsies of child deaths from violence and neglect in the Suez Canal area, Egypt. Egyptian Journal of Forensic Sciences, 3:116-122.

El-Hak, S.A., Ali, M.A., and El-Atta, H.M. (2009): Child deaths from family violence in Dakahlia and Damiatta Governorates, Egypt. Journal of Forensic \& Legal Medicine Oct, 16:388-391. 10.1016/j.jflm.2009.04.010. 
Gilbert, R., Widom, C.S., Browne, K., Fergusson, D., Webb, E., and Janson, S. (2009): Burden and consequences of child maltreatment in high-income countries. Lancet, January 3, 373:68-81.

Glaser, D. (2002): Emotional abuse and neglect (psychological maltreatment): A conceptual framework. Child Abuse \& Neglect, 26:697-714.

Janson, S., Långberg, B., and Svensson, B. (2007): Violence against Children in Swedish. Stockholm 2006-2007.

Jenny, C. and Isaac, R. (2006): The relation between child death and child maltreatment. Archives of Disease in Childhood, 91:265-269.

Leeb, R.T., Paulozzi, L.J., Melanson, C., Simon, T.R., and Arias, I. (2008): Child Maltreatment Surveillance: Uniform Definitions for Public Health and Recommended Data Elements. Centers for Disease Control and Prevention.

May-Chahal, C., Cawson, P. (2005): Measuring child maltreatment in the United Kingdom: A study of the prevalence of child abuse and neglect. Child Abuse \& Neglect, 29:969-984.

Montgomery, H. (2006): Different cultures, different childhoods Open Learn: The home of free learning from the

OpenUniversity:http://www.open.edu/ openlearn/history-thearts/history/different-cultures different,http://dx. 10.1016/S13591789(98)00014-7.

Mouzos, J. and Makkai, T. (2004): Women's Experiences of Male Violence: Findings from the Australian Component of the International Violence against Women Survey (IVAWS). Australian Institute of Criminology; (research and public policy series no. 56).

Pinheiro, P.S. (2006): World report on violence against children. New York: United Nations (Released, 2006-1011).
Radford L, Corral S, Bradley C, Fisher H, Bassett C, Howat N, et al. (2011): Child abuse and neglect in the UK. Today. London: NSPCC (03)(0003):4-6. 10.1016/S0145-2134.

Roshdy, Mansour, K., Daoud, O.A., Langdon, P.E., El-Saadawy, M., AlZahrani, A., and Shafi, A. (2010): Khashaba. Arab Journal of Psychiatry: Child Abuse and its Long-Term Consequences: An Exploratory Study on Egyptian University Students, 21 No.2:(137-163).

Saad, S., Salama, K.M., and Moghazy, A. (2016): Incidence, topography, types of firearm injuries before and after the revolution of the 25 th of January 2011: A hospital-based study. International Surgery Journal:11931198 Aug: 1193-1198 http://www.ijsurgery.com pISSN, 3:2349-3305 | eISSN 2349-2902.

Sandre, A., Ethridge, P., Kim, I., Weinberg, A. (2018): Childhood maltreatment is associated with increased neural response to ambiguous threatening facial expressions in adulthood: Evidence from the late positive potential. Cognitive, Affective \& Behavioral Neuroscience, 18:143-154. 10.3758/s13415-017-0559-z.

Sumner, S.A., Mercy, J.A., Dahlberg, L.L., Hillis, S.D., Klevens, J., Houry, D. (2015): Violence in the United States: Status, challenges, and opportunities. JAMA, 314:478-488. 10.1001/jama.2015.8371.

Tjaden, P. and Thoennes, N. (1998): Prevalence, Incidence, and Consequences of Violence against Women: Findings from the National Violence against Women Survey. Research in Brief.

Townsend, C. (2013): Prevalence and consequences of child sexual abuse compared with other childhood experiences. Available from: www.D2L.org. Charleston, S.C.: Darkness to Light (Released, August 
2013).

Walsh, B. (2005): Investigating child fatalities: Portable guides to investigating child abuse. Available from:

https://www.ncjrs.gov/pdffiles1/ojjdp/ 209764.pdf. Office of Justice Programs.

Weltz, S.M., Armeli, S., Ford, J.D., and Tennen, H. (2016): A daily process examination of the relationship between childhood trauma and stress- reactivity. Child Abuse \& Neglect, 60:1-9.

WHO. (2020): Child maltreatment ('child abuse'). Available from: https://www.who.int/news-room/factsheets/detail/child-maltreatment.

Wihbey, J. (2011): Global prevalence of child sexual abuse. Journalist Resource. Available from: Journalistsresource.org/studies/./ global-prevalence-child-sexual-abuse. 


\section{حالات إساءة معاملة الأطفال المحالة إلى قسم الطب الشرعي بسوهاج، وزارة

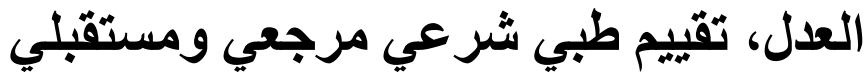

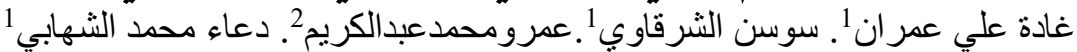

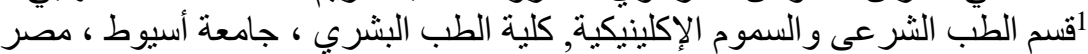

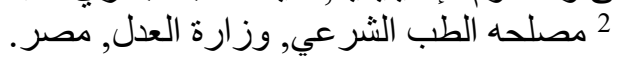

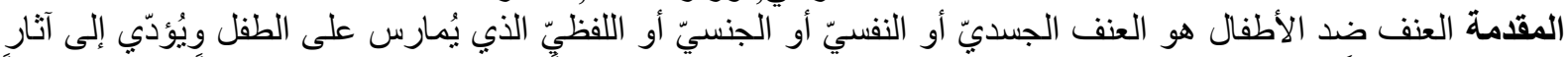

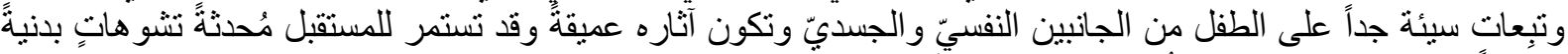

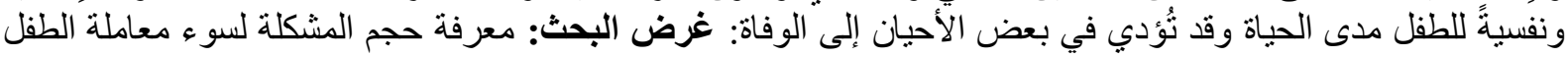

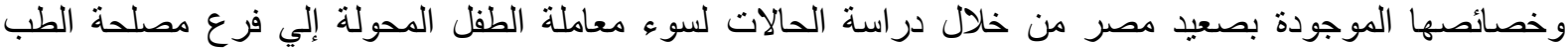

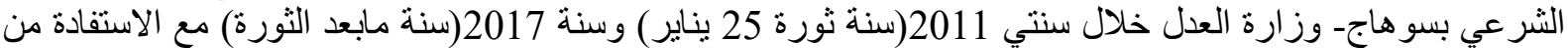

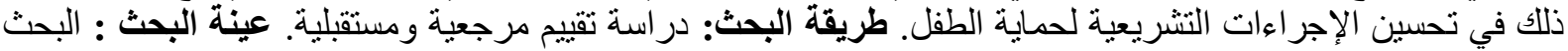

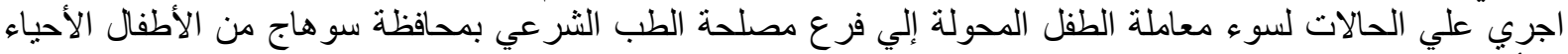

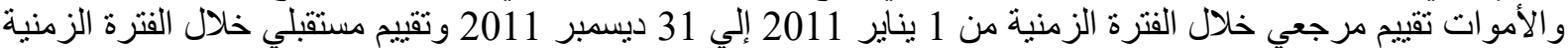

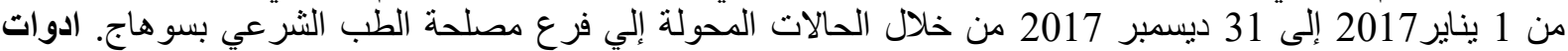

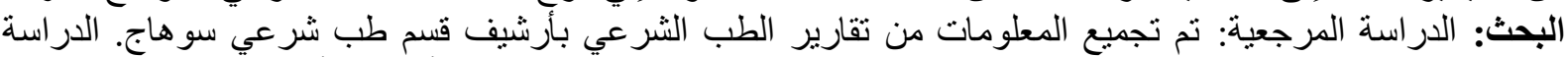

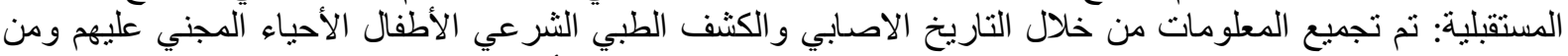

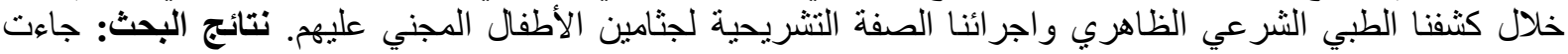

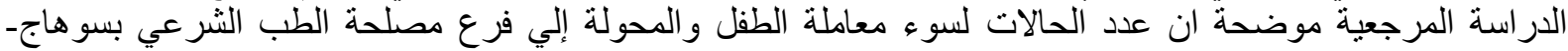

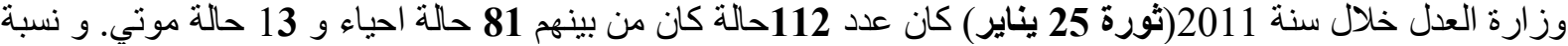

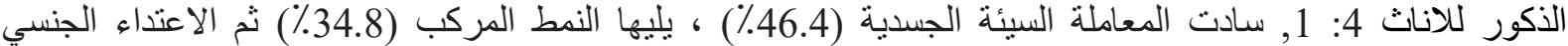

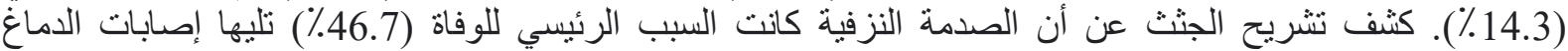

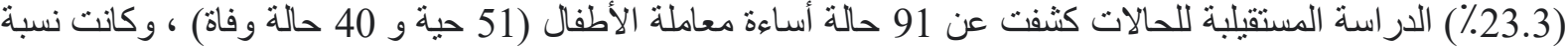

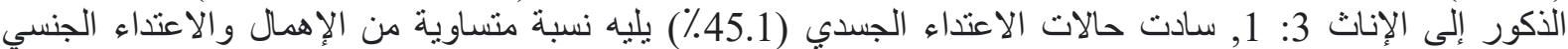

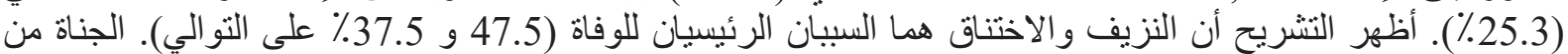

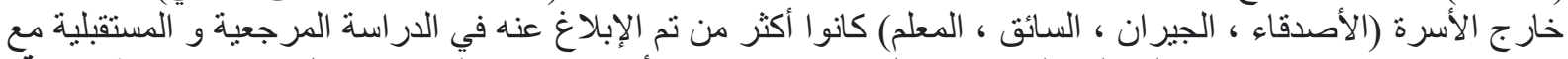

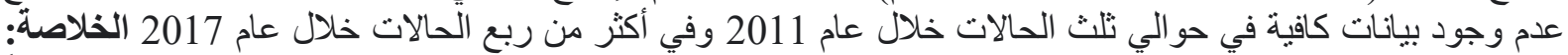

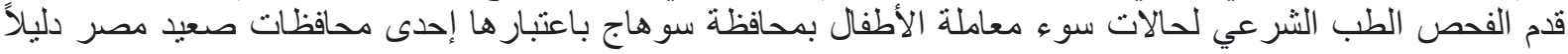

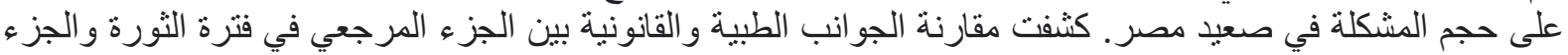

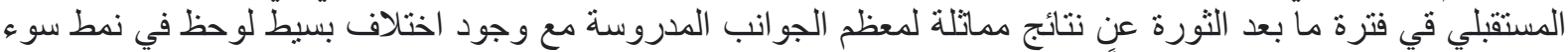

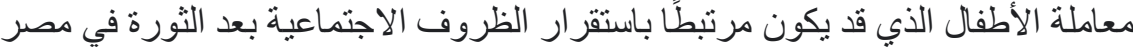

